\title{
Interrelationships among stock prices of Taiwan and Japan and NTD/Yen exchange rate
}

\author{
Hwey-Yun Yau ${ }^{\mathrm{a}, 1}$, Chien-Chung Nieh ${ }^{\mathrm{b}, *}$ \\ ${ }^{\text {a }}$ Department of Accounting and Information, National Taipei College of Business, Taipei, Taiwan \\ ${ }^{\mathrm{b}}$ Department of Banking and Finance, Tamkang University, Tamsui, Taipei 251, Taiwan \\ Received 15 December 2005; received in revised form 17 April 2006; accepted 24 April 2006
}

\begin{abstract}
Since the Asian Financial Crisis in 1997, the relationship between stock prices and exchange rates has received considerable amount of attention from the economists, international investors and policy makers. The work reported here employs various linear and non-linear, time-series methodologies to investigate the short-term and long-term interrelationships among the stock prices of Taiwan and Japan and the NTD/Yen exchange rate during the period of January 1991-July 2005. The findings from this study include: firstly, the stock prices of Taiwan and Japan impact each other for short durations; secondly, with regard to relationship between stock prices and exchange rates, the portfolio approach is supported for the short-term and the traditional approach is more plausible for the long-term in the Taiwanese financial market, whereas the portfolio approach is not suitable for the Japanese stock market; and thirdly, there appears to be no long-term relation between NTD/Yen exchange rate and the stock prices of Taiwan and Japan.

(C) 2006 Elsevier Inc. All rights reserved.
\end{abstract}

Keywords: Exchange rate; Stock price; Structural break; Granger causality

\section{Introduction}

The Asian Financial Crisis (AFC) in 1997 struck the economy of many Asian countries. They have experienced the continuous devaluation of their domestic currencies and severe hit against the stock markets. However, the financial and economic conditions in these countries have since gradually recovered. Nevertheless, the issue of whether stock prices and exchange rates are related has brought out considerable attention from the economists, international

\footnotetext{
* Corresponding author. Tel.: +88622621 5656x2591; fax: +886226214755.

E-mail addresses: yauhy@mail.ntcb.edu.tw (H.-Y. Yau), niehcc@mail.tku.edu.tw (C.-C. Nieh).

${ }^{1}$ Tel.: +88622393 5263x6365.
} 
investors and policy makers. Empirically or theoretically, many economists suggested a significant relationship between exchange rates and stock prices. ${ }^{2}$ However, the results are quite mixed with the sign and causal direction between exchange rates and stock prices. ${ }^{3,4}$ Mok (1993) found weak bi-directional causality between stock prices and the exchange rates, while Bahmani-Oskooee and Sohrabian (1992) and Nieh and Lee (2001) argued for a bidirectional causality between stock prices and exchange rates in the short run but not in the long run.

Because the total value of Japanese international trade is placed third globally, second only to America and Germany, Japan plays a very important role in the global economic and financial system. On the other hand, Taiwan's economy is highly open to international trade and investment. Thus the volatility of exchange rate of the New Taiwan Dollar (NTD) against the currencies of Taiwan's major trading partners (e.g. the US Dollar and the Japanese Yen) may affect both the exporters and importers significantly in Taiwan. For instance, if the exchange rate appreciates, exporters will lose their competitiveness in international markets. Their profits will shrink, and the stock prices will drop. On the contrary, if the exchange rate depreciates, importers will lose their competitiveness in domestic markets (consumers may not afford to purchase "higher-price" imported products), their sales and profits will be reduced, and the stock prices will drop as a result.

Due to the mutual effects of exchange rates on stock prices as mentioned above, it is difficult to predict the overall impact of the varying exchange rate on the Taiwanese and Japanese stock markets. Whether it is favorable or unfavorable depends on the entire industrial structure within a country. Studies emphasizing on the impact of the exchange rate on stock price for Taiwan can be found in Wu (1997), Guo and Wu (1998) and Chiao, Hung, and Nwanna (2001); whereas Choi, Hiraki, and Takezawa (1998), He and Ng (1998), Doukas, Hall, and Lang (1999), Caporale, Pittis, and Spagnolo (2002), Elyasiani and Mansur (2005) and Homma, Tsutsui, and Benzion (2005) among others, studied the relationship between the exchange rate and stock price of Japan.

For an extended period of time Taiwan has experienced a widening trade gap (deficit) with Japan. The main explanation could be that the majority of Taiwan imports from Japan are more capital-intensive and comparable expensive goods; while the majority of Taiwan exports to Japan are more labor-intensive and cheaper goods. This degenerating condition of trade imbalance with Japan has remained unchanged so far. In fact, for any country faced with a high trade deficit, the obvious way to solve this problem is either with quantitative restrictions, or high duties on imports, or a devaluation of domestic currency. However, there is no perfect solution among these three options. In particular, the way of devaluation may involve some inflationary consequences to the extent it raise prices of imports. This problem still requires attention because the more open

\footnotetext{
${ }^{2}$ For instance, Aggarwal (1981), Soenen and Hennigar (1988), Smith (1992), Bodnar and Gentry (1993), Barton and Bodnar (1994), Dropsy and Nazarian-Ibrahimi (1994), Choi and Prasad (1995), Prasad and Rajan (1995), Ajayi and Mougoue (1996), Fang and Loo (1996), Abdalla and Murinde (1997), Kwon, Shin, and Bacon (1997), Kanas (2000) and Bhattacharya and Mukherjee (2003) among others.

${ }^{3}$ The traditional approach claims that a depreciation of domestic currency makes local firms more competitive and results in an increase in their export, which in turn raises their firms' value and their stock prices. This implies a positive relationship between exchange rates (by American quotation) and stock prices. On the other hand, the portfolio approach argues that an increase in stock price induces investors to demand for more domestic assets and thereby causes an appreciation in domestic currency, which implies that stock prices and exchange rates are negatively related.

${ }^{4}$ By European quotation, the relationship between stock prices and exchange rates of traditional or portfolio approach is just the reverse.
} 
the economy of a country is, the more vulnerable it is to macroeconomic shocks from abroad through shifts in the trade balance. Additionally, as an export-oriented country, Taiwan heavily depends on electronics products exported to its major trading partners. Japan, like most of the other Asia-Pacific countries, is a main competitor to Taiwan. In the case when the exchange rate of NTD against Japanese Yen (NTD/Yen) appreciates, Taiwan exporters may lose their competitiveness in the world markets and their stock prices would shrink. Studies investigating the causal relations and the international transmission between these two financial assets of Japan and Taiwan can also be found in Sewell, Stansell, Lee, and Below (1996), Chen and Wu (1997), Granger, Huang, and Yang (2000) and Pilbeam (2001).

In prior empirical studies concerning the exchange rate, the US dollar was mostly utilized as the base-currency, while a few studies used the Japanese Yen instead. ${ }^{5,6}$ Because Japan is one of the major trading partners of Taiwan, the exchange rate of the NTD/Yen plays a crucial role and may possibly influence Taiwan's economy as well as stock market. Therefore, while investigating the relationship or financial transmission between these two countries, it may be more appropriate to consider Yen as the base-currency (i.e. NTD/Yen in this paper).

The main purpose of our study is to fully investigate the dynamic short-term causal relations and the long-term equilibrium relations between these two major financial assets, the stock prices of Japan and Taiwan and the exchange rate, by employing various conventional and advanced time-series techniques. The findings of the lead-lag relations and the long-term co-movements among the three variables considered may provide the multinational enterprises and the international investors an excellent reference for their asset allocations.

More recently, it has been suggested that linear conventional time series methodologies fail to consider information across regions, and lead to inefficient estimations and lower testing power. One proposed approach to increase power in testing is to consider the use of non-linear techniques. In this study, we attempt to employ the advanced time-series methodologies, incorporating the endogenous structural break, namely Zivot and Andrews (1992) (hereafter ZA) for the unit root test and Gregory and Hansen (1996) (hereafter GH) for co-integration, to investigate and analyze the dynamic short-term causal relations and long-term co-movements among the three variables considered.

The remainder of this paper is organized as follows: Section 2 describes the data used in this study, Section 3 introduces the methodologies used, Section 4 presents the empirical results, and Section 5 concludes this paper.

\section{Data}

This research is conducted using the basis of the NTD/Yen exchange rate, ${ }^{7}$ closing Taiwan Stock Exchange Index (TW stock) and the Nikkei 225 Index (JP stock). Data are collected from the AREMOS Statistical Data Bank of Ministry of Education, Taiwan. The sample period runs from January 1991 to July 2005, for a total of 175 monthly observations are obtained for each variable. This specific period is chosen due to the fact that the 1997 Asian Financial Crisis

\footnotetext{
${ }^{5}$ Enders and Hurn (1994) believed that using Japanese Yen as the base-currency can be crucial in investigating the macro-fundamental issues, especially among the Asian countries.

${ }^{6}$ The issue examining the dominant power or considering of the impact of either the US or Japan on other countries' financial markets can be found in Karolyi and Stulz (1996), Varela and Naka (1997), Sun and Tong (2000) and Durand, Kee, and Watson (2001).

${ }^{7}$ The NTD/Yen exchange rate adopted in this paper is a nominal closing exchange rate at the end of each month.
} 


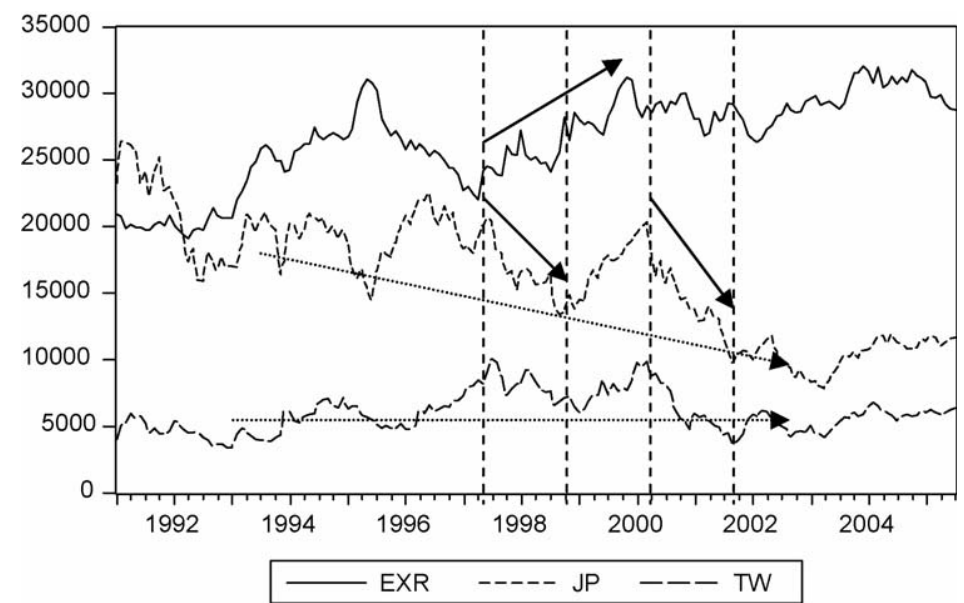

Fig. 1. Trends of NTD/Yen exchange rate (EXR), Nikkei 225 index (JP) and Taiwan stock index (TW). Note: NTD/Yen exchange rate is multiplied by 100,000 to enlarge the scare for easier comparison.

happened in the middle of this period, thus we may capture a full picture of before and after the crisis (see Fig. 1). We observe from Fig. 1 that both stock indices had experienced a similar upand-down moving pattern. However, the volatility of the JP stock is much higher than that of the TW stock, and the JP stock is in fact in a downward trend through all the sample period. Moreover, it is seen clearly that, after the AFC, Yen appreciated against NTD up to the year 2000. During this period, the fluctuation of the TW stock was moderate, whereas JP stock had experienced a dramatic decrease before the month of September 1998 when it hit its local lowest of 13,406 from its local highest of 20,604 in June 1997. The second serious drop in the JP stock index from 20,337 to 9775 took place in the period between March 2000 and September 2001. This illustrates that the JP stock was heavily impacted in 2000 during the worldwide internet bubble. Fig. 1 also shows that the increase in JP stock most likely accompanies the Yen depreciation (again NTD), whereas the TW stock increases with the NTD appreciation (against Yen).

\section{Methodologies}

This paper utilizes various time-series models, conventional linear and advanced non-linear algorithms, to analyze the long-term and short-term interrelationships among stock prices of Taiwan, Japan, and the NTD/Yen exchange rate.

\subsection{Unit root tests}

\subsubsection{Conventional linear unit root tests}

Among various testing strategies, this paper firstly tests for "stationarity" of each variable by employing three traditional unit-root test techniques, ADF (Dickey \& Fuller, 1981), PP (Phillips $\&$ Perron, 1988) and NP (Ng \& Perron, 2001). ${ }^{8}$

\footnotetext{
${ }^{8}$ The test statistic of NP test is $\mathrm{MZ}_{t}$ in this paper.
} 
According to Schwert (1989), the ADF test with long lags is superior to the others. ${ }^{9}$ The three differencing AR models of ADF are expressed as the following forms:

$$
\begin{aligned}
& \Delta y_{t}=\phi y_{t-1}+\sum_{i=1}^{p-1} \beta_{i} \Delta y_{t-i}+\varepsilon_{t} \\
& \Delta y_{t}=\alpha+\phi y_{t-1}+\sum_{i=1}^{p-1} \beta_{i} \Delta y_{t-i}+\varepsilon_{t} \\
& \Delta y_{t}=\alpha+\phi y_{t-1}+\gamma t+\sum_{i=1}^{p-1} \beta_{i} \Delta y_{t-i}+\varepsilon_{t}
\end{aligned}
$$

Model (1) is a pure random walk with the lag terms. Model (2) possesses a drift. Model (3) includes a drift and a time trend. The null hypothesis for ADF test is: $\mathrm{H}_{0}: \phi=0$, with the alternative $\mathrm{H}_{1}:-2<\phi<0$.

Hamilton (1994) and Elder and Kennedy (2001) both argued that a strategy is necessary to determine which of the three ADF models should be employed in conducting the unit root test. ${ }^{10}$ In this paper, we follow the determining rule by Dolado, Jenkinson, and Sosvilla-Rivero (DJS) (1990) to determine the appropriate model for each variable. ${ }^{11}$

The PP test for unit roots adopts the basic ADF-related hypothesis, which first calculates the ADF statistics and modifies them to PP statistical values (Phillips-type test) under the circumstance that the error term is allowed to be of weak dependency and heterogeneous variance. In a later research, $\mathrm{Ng}$ and Perron (2001) modified $Z_{\alpha}$ and $Z_{t}$ statistics of PP test and further constructed four test statistics, known as NP unit root test.

Since the estimation might be biased if the lag length and bandwidth are pre-designated without rigorous determination, based on the "principle of parsimony", our unit root tests utilize Modified Akaike information criterion (MAIC) suggested by Ng and Perron (2001) for ADF and NP and Bartlett kernel based criterion proposed by Newey and West (1994) for PP to determine the optimal number of lags and optimal bandwidth, respectively.

\subsubsection{Advanced non-linear unit root test with structural break-ZA test}

One major drawback of conventional unit root tests is in the implicit assumption that the deterministic trend is correctly specified. Perron (1989), which developed a unit root model with an exogenous structural break, argued that if there is a break in the deterministic trend, the unit root test will lead to a misleading conclusion that there is a unit root when in fact there is not. Further elaborated work by Zivot and Andrews (1992) overthrew the presumed exogenous break point and developed a unit root test with endogenous structural break, which has been regarded as a more suitable test for the stationarity of series. The three models of ZA tests are expressed as the

\footnotetext{
${ }^{9}$ Ayat and Burridge (2000) also argued that the ADF test has become the most popular of many competing tests in the literature.

${ }^{10}$ Elder and Kennedy (2001) developed a student-friendly testing strategy in determine the appropriate ADF model by applying traditional OLS method.

${ }^{11}$ The determining rule by DJS (1990) is to test for the significance of trend coefficient in the third model first, followed by testing for the significance of the drift coefficient in the second model. If both outcomes result in insignificant, the first model is selected.
} 
following forms

$$
\begin{aligned}
& \text { Model A : } \Delta Y_{t}=\mu_{1}^{\mathrm{A}}+\gamma_{1}^{\mathrm{A}} t+\mu_{2}^{\mathrm{A}} \mathrm{DU}_{t}(\lambda)+\alpha^{\mathrm{A}} Y_{t-1}+\sum_{j=1}^{k-1} \beta_{j} \Delta Y_{t-j}+\varepsilon_{t} \\
& \text { Model B : } \Delta Y_{t}=\mu_{1}^{\mathrm{B}}+\gamma_{1}^{\mathrm{B}} t+\gamma_{2}^{\mathrm{A}} \mathrm{DT}_{t}^{*}(\lambda)+\alpha^{\mathrm{B}} Y_{t-1}+\sum_{j=1}^{k-1} \beta_{j} \Delta Y_{t-j}+\varepsilon_{t} \\
& \text { Model C : } \Delta Y_{t}=\mu_{1}^{\mathrm{C}}+\gamma_{1}^{\mathrm{C}} t+\mu_{2}^{\mathrm{C}} \operatorname{DU}_{t}(\lambda)+\gamma_{2}^{\mathrm{C}} \mathrm{DT}_{t}^{*}(\lambda)+\alpha^{\mathrm{C}} Y_{t-1}+\sum_{j=1}^{k-1} \beta_{j} \Delta Y_{t-j}+\varepsilon_{t}
\end{aligned}
$$

where $\mathrm{DU}_{t}(\lambda)$ is 1 and $\mathrm{DT}_{t}^{*}(\lambda)=t-T \lambda$ if $t>T \lambda, 0$ otherwise. $\lambda=T_{\mathrm{B}} / T$ and $T_{\mathrm{B}}$ represents a possible break point. Model A allows for a change in the level of the series, Model B allows for a change in the slope of trend of a series, while Model C combines both changes in the level and the slope of trend. Since the appropriate model and the optimal lag lengths are crucial in interpreting the results of the tests, we adopt the findings from the ADF tests to select the model and the lag lengths for the ZA tests.

\subsection{Co-integration test}

\subsubsection{Johansen's co-integration test}

Various methods of estimating co-integration have been applied to capture the long-run equilibrium relationship among the variables. Among those, Johansen methodology based on the likelihood ratio with non-standard asymptotic distributions involving integrals of Brownian motions is found to be the best method to proceed with co-integration estimation by Gonzalo (1994). ${ }^{12}$

The elaborate works developed by Johansen $(1988,1990,1994)$ are summarized into five VAR models with ECM, which are presented in the following forms ${ }^{13}$ :

$$
\begin{aligned}
& \mathrm{H}_{0}(r): \Delta X_{t}=\Gamma_{1} \Delta X_{t-1}+\cdots+\Gamma_{k-1} \Delta X_{t-(k-1)}+\alpha \beta^{\prime} X_{t-1}+\Psi D_{t}+\epsilon_{t} \\
& \mathrm{H}_{1}^{*}(r): \Delta X_{t}=\Gamma_{1} \Delta X_{t-1}+\cdots+\Gamma_{k-1} \Delta X_{t-(k-1)}+\alpha\left(\beta^{\prime}, \beta_{0}\right)\left(X_{t-1}^{\prime}, 1\right)^{\prime}+\Psi D_{t}+\epsilon_{t}
\end{aligned}
$$

$$
\mathrm{H}_{1}(r): \Delta X_{t}=\Gamma_{1} \Delta X_{t-1}+\cdots+\Gamma_{k-1} \Delta X_{t-(k-1)}+\alpha \beta^{\prime} X_{t-1}+\mu_{0}+\Psi D_{t}+\epsilon_{t}
$$

$$
\mathrm{H}_{2}^{*}(r): \Delta X_{t}=\Gamma_{1} \Delta X_{t-1}+\cdots+\Gamma_{k-1} \Delta X_{t-(k-1)}+\alpha\left(\beta^{\prime}, \beta_{1}\right)\left(X_{t-1}^{\prime}, t\right)^{\prime} \mu_{0}+\Psi D_{t}+\epsilon_{t}
$$

$$
\mathrm{H}_{2}(r): \Delta X_{t}=\Gamma_{1} \Delta X_{t-1}+\cdots+\Gamma_{k-1} \Delta X_{t-(k-1)}+\alpha \beta^{\prime} X_{t-1}+\mu_{0}+\mu_{1} t+\Psi D_{t}+\epsilon_{t}
$$

\footnotetext{
12 Gonzalo (1994) compared several methods of estimating co-integration, which include ordinary least squares, nonlinear least squares, maximum likelihood in an error correction model, principle components, and canonical correlations

${ }^{13}$ The 1990 equation form is from Johansen and Juselius (1990).
} 
To analyze the deterministic term, Johansen decomposed the parameters $\mu_{0}$ and $\mu_{1}$ in the directions of $\alpha$ and $\alpha_{\perp}$ as $\mu_{i}=\alpha \beta_{i}+\alpha_{\perp} \gamma_{i}$, thus we have $\beta_{i}=\left(\alpha^{\prime} \alpha\right)^{-1} \alpha^{\prime} \mu_{i}$ and $\gamma_{i}=\left(\alpha_{\perp}{ }^{\prime} \alpha_{\perp}\right)^{-1} \alpha_{\perp}^{\prime} \mu_{i}$. The nested sub-models of the general model of null hypothesis $\Pi=\alpha \beta^{\prime}$ are, therefore, defined as:

$$
\begin{array}{ll}
\mathrm{H}_{0}(r): & Y=0 \\
\mathrm{H}_{1}^{*}(r): & Y=\alpha \beta_{0} \\
\mathrm{H}_{1}(r): & Y=\alpha \beta_{0}+\alpha_{\perp} \gamma_{0} \\
\mathrm{H}_{2}^{*}(r): & Y=\alpha \beta_{0}+\alpha \perp \gamma_{0}+\alpha \beta_{1} t \\
\mathrm{H}_{2}(r): & Y=\alpha \beta_{0}+\alpha_{\perp} \gamma_{0}+\left(\alpha \beta_{1}+\alpha_{\perp} \gamma_{1}\right) t
\end{array}
$$

Johansen (1994) emphasized the role of the deterministic term, $Y=\mu_{0}+\mu_{1} t$, which includes constant and linear terms in the Gaussian VAR. A decision procedure, following Nieh and Lee (2001) among the hypotheses $\mathrm{H}(r)$ and $\mathrm{H}^{*}(r)$ of the above five different models, is presented in the following procedure ${ }^{14}$ :

$$
\begin{aligned}
& \mathrm{H}_{0}(0) \rightarrow \mathrm{H}_{1}^{*}(0) \rightarrow \mathrm{H}_{1}(0) \rightarrow \mathrm{H}_{2}^{*}(0) \rightarrow \mathrm{H}_{2}(0) \rightarrow \mathrm{H}_{0}(1) \rightarrow \mathrm{H}_{1}^{*}(1) \rightarrow \mathrm{H}_{1}(1) \rightarrow \mathrm{H}_{2}^{*}(1) \\
& \quad \rightarrow \mathrm{H}_{2}(1) \rightarrow \cdots \rightarrow \cdots \rightarrow \mathrm{H}_{0}(p-1) \rightarrow \mathrm{H}_{1}^{*}(p-1) \rightarrow \mathrm{H}_{1}(p-1) \rightarrow \mathrm{H}_{2}^{*}(p-1) \\
& \quad \rightarrow \mathrm{H}_{2}(p-1)
\end{aligned}
$$

We diagnose models one by one until the model that cannot be rejected for the null.

\subsubsection{Advanced non-linear co-integration test with structural break-GH test}

The GH tests are considered as a multivariate extension of the univariate ZA unit root test. Besides, it expands conventional linear test to enable testing over periods incorporating structural breaks. The possibility of unit roots being affected by structural change can also be the case with tests for co-integration. The GH test is a residual-based test, which test the null of no cointegration against the alternative of co-integration in the presence of a possible regime shift. ${ }^{15}$ The shift considered is a single break in the intercept and/or slope coefficients vector. Four models of GH tests are proposed in Gregory and Hansen (1996). Model (1) is the standard Engle and Granger (1987) two-stage co-integration methodology, the other three models are expressed as the following equations:

$$
\begin{aligned}
& \text { Model 2 }(C): y_{t}=\mu_{1}+\mu_{2} D_{t}(\lambda)+\beta_{1} X_{t}+e_{t} \\
& \text { Model 3 }(C / T): y_{t}=\mu_{1}+\mu_{2} D_{t}(\lambda)+\gamma t+\beta_{1} X_{t}+e_{t} \\
& \text { Model 4 }(C / S): y_{t}=\mu_{1}+\mu_{2} D_{t}(\lambda)+\beta_{1} X_{t}+\beta_{2} X_{t} D_{t}(\lambda)+e_{t}
\end{aligned}
$$

where $y_{t}$ is an univariate, and $X_{t}$ is variate vector. If $t>T \lambda(t=1, \ldots, T), D_{t}(\lambda)$ equals 1,0 otherwise. $\lambda=T_{\mathrm{B}} / T$ and $T_{\mathrm{B}}$ represents a possible break point.

The test statistics for the ADF, and $Z_{\alpha}$ and $Z_{t}$ of Perron (1989) are:

$$
\mathrm{ADF}^{*}=\inf _{\tau \in T} \operatorname{ADF}(\tau) \quad Z_{\alpha}^{*}=\inf _{\tau \in T} Z_{\alpha}(\tau) \quad Z_{t}^{*}=\inf _{\tau \in T} Z_{t}(\tau)
$$

\footnotetext{
${ }^{14}$ Johansen $(1992,1994)$ developed a testing procedure based on the ideas developed by Pantula (1989) to determine the number of co-integrating rank in the presence of linear trend (Johansen, 1992) and quadratic trend (Johansen, 1994). 15 The residuals are tested to determine if they are $\mathrm{I}(0)$ or $\mathrm{I}(1)$ processes. Rejection of the null implies an $\mathrm{I}(0)$ residual and, therefore, indicates the presence of co-integration.
} 


\subsection{Granger's causality test (GC test)}

If the variables are non-stationary and co-integrated, the adequate method to examine the causal relations is the Vector Error Correction Model (VECM) (Granger, 1988); otherwise a VAR model is used in the case of no co-integration found among the variables (Granger, 1969). ${ }^{16}$

The standard GC test then examines if there exists feedback (bi-directional) or one-way causality between variables. Considering two series, $X_{t}$ and $Y_{t}$, the GC test is in the form as follows:

$$
\begin{aligned}
& \Delta X_{t}=\alpha_{1}+\sum_{i=1}^{n_{1}} \alpha_{11}(i) \Delta X_{t-i}+\sum_{j=1}^{m_{1}} \alpha_{12}(j) \Delta Y_{t-j}+\epsilon_{X t} \\
& \Delta Y_{t}=\alpha_{2}+\sum_{i=1}^{n_{2}} \alpha_{21}(i) \Delta X_{t-i}+\sum_{j=1}^{m_{2}} \alpha_{22}(j) \Delta Y_{t-j}+\epsilon_{Y t}
\end{aligned}
$$

where $\epsilon_{X t}$ and $\epsilon_{Y t}$ are stationary random processes intended to capture other pertinent information not contained in lagged values of $X_{t}$ and $Y_{t}$. The lag lengths, $n$ and $m$, are decided by AIC in our study. The series $Y_{t}$ fails to Granger cause $X_{t}$ if $\alpha_{12}(j)=0\left(j=1,2,3, m_{1}\right)$; and the series $X_{t}$ fails to cause $Y_{t}$ if $\alpha_{21}(i)=0\left(i=1,2,3, n_{1}\right)$.

\subsection{Generalized impulse response functions and variance decompositions ( $G$-IRF and G-VDC)}

The more recent researches have largely applied the impulse response functions (IRF) and variance decompositions (VDC) to conquer the difficulty of interpreting the estimated coefficients of a VAR model. An IRF traces the response of current and future values of the endogenous variables to a one standard deviation shock through the dynamic structure of the VAR. The IRF is in the following expression:

$$
X_{t}=\mu+\sum_{i=0}^{\infty} \Phi_{j k}(i) \varepsilon_{t-i}
$$

where $\mu$ is a $3 \times 1$ vector of constants, $\varepsilon_{t-i}$ is a $3 \times 1$ error vector, $\Phi_{j k}(i)$ is a $3 \times 3$ matrix with $\Phi_{j k}(0)=I_{3}$ and elements of $\Phi_{j k}(i)$ are the "impact multipliers", which examine the interaction among NTD/Yen, JP stock and TW stock over the entire path. ${ }^{17}$

VDC, on the other hand, decomposes forecast error variance (FEV) in an endogenous variable into percentage shocks to its own and other endogenous variables in the VAR, which in turn offers information about the relative importance (exogenous ordering) of each random innovation to the variables.

The corresponding variance-covariance matrix of the $k$-step ahead forecast error and its decomposition can be expressed as follows:

$$
\begin{aligned}
& E\left(X_{t}-\hat{E}_{t-k} X_{t}\right)\left(X_{t}-\hat{E}_{t-k} X_{t}\right)^{\prime} \\
& \quad=D_{0} E\left(\mu_{t} \mu_{t}^{\prime}\right) D_{0}^{\prime}+D_{1} E\left(\mu_{t} \mu_{t}^{\prime}\right) D_{1}^{\prime}+\cdots+D_{k-1} E\left(\mu_{t} \mu_{t}^{\prime}\right) D_{k-1}^{\prime}
\end{aligned}
$$

\footnotetext{
16 The Engle and Granger's (1987) "Granger representation theorem" argued that error correction and co-integration are equivalent representations.

17 The number of three represents three variables of NTD/Yen exchange rate, Taiwan stock exchange index and the Nikkei 225 index of Japan.
} 
where $\quad \hat{E}_{t-k} x_{T}=D\left[x_{t} \mid x_{t-k}, x_{t-k-a}, x_{t-k-2}, \ldots\right], \quad X_{t} \quad$ is $\quad$ VMA representation of $X_{t}=\alpha^{\prime}+\sum_{i=0}^{\infty} C_{i} \varepsilon_{t-i}, D_{i}=C_{i} V, \mu_{t-1}=V^{\prime} \varepsilon_{t-i}, C_{i}$ is a $3 \times 3$ matrix with $C_{0}=I_{3}$, and $V$ is a $3 \times 3$ lower triangular matrix of the Choleski decomposition.

Cooley and LeRoy (1985) criticize that orthogonalized IRF and VDC based on Choleski decomposition are, in general, not meaningful. King, Plosser, Stock, and Watson (1999) and Zhou (1996) further pointed out that as there is more than one common trend in a model, different ordering of variables may significantly affect the results of IRF and VDC if the common trends are not absolutely uncorrelated. The newly developed generalized-VAR (the G-IRF and G-VDC) models by Pesaran and Shin (1998) overwhelm the shortcoming of orthogonalized IRF and VDC, which have the advantage of being invariant to the ordering of the variables. ${ }^{18}$ Dekker, Sen, and Young (2001) compared traditional VAR with G-VAR in estimating linkages of the Asia Pacific equity markets. It was found that the generalized approach significantly gives more realistic results, particularly for those markets with closest geographical and economic links. Other literature applying G-IRF for the interactions among variables can also be found in Ewing (2003), Peel and Venetis (2003) and Hacker and Hatemi-J (2003).

\section{Empirical results}

Firstly, the results of the three unit root tests, ADF, PP and NP, are summarized in Table 1, which show that the null of non-stationarity cannot be rejected for any levels of the series. After first differencing, however, the null is rejected at least at the 5\% significance level for all series. We thus conclude that all the variables considered in this paper are the I(1) type series.

We further adopt the advanced ZA non-linear unit root test considering a structural break. The results of the ZA test are presented in Table 2 and shown in Fig. 2. All three variables carry unitroot in the level and reject the null of "non-stationarity" in the first difference. This again insures the I(1) type series for all the variables considered. The same order of integration among nonstationary series found from both linear and non-linear tests enable us to go further co-integration tests.The empirical findings for the long-run relationship through Johansen co-integration tests considering of both a linear trend and a quadratic trend among NTD/Yen, JP stock and TW stock are summarized in Table 3. The lag lengths for our models of co-integration are two based on the smallest number of AIC. We follow Nieh and Lee (2001) decision procedure described in Section 3 among the hypotheses $\mathrm{H}(r)$ and $\mathrm{H}^{*}(r)$ of the five Johansen models. The result shows that no cointegrating vector is found. This indicates that there exists no long-run equilibrium or comovement relationship among stock prices of Taiwan and Japan and exchange rate of NTD/Yen.

The Gregory and Hansen (1996) test expands previous Johansen's test to enable testing over periods incorporating structural breaks. Consistent with the finding from the above Johansen tests, the results of the GH test, shown in Table 4, reveal no co-integration relationship among the three variables in the presence of a possible regime shift.

Since the results from the former Johansen and GH tests indicate no co-integration existing among the three variables considered, we simply apply Granger (1969) VAR model to test the causal relationship between each set of pairwise variables. The results of the GC test are shown in Table 5 that bi-directional causality was revealed between stock prices of Taiwan and Japan.

\footnotetext{
${ }^{18}$ After discussing advantages and disadvantages of traditional impulse response functions for non-linear models, the concept of a generalized impulse response function, which is applicable to both linear and non-linear models, is first introduced by Koop, Pesaran, and Potter (1996).
} 
Table 1

The results of various unit root tests

\begin{tabular}{|c|c|c|c|c|c|c|}
\hline & JP Stock & & TW Stock & & EX Rate & \\
\hline \multicolumn{7}{|l|}{$\mathrm{ADF}$} \\
\hline Level & -2.860 & [3] $(0)$ & -2.487 & [2] $(0)$ & -1.976 & [2] (6) \\
\hline First difference & $-5.052^{* * *}$ & [1] (4) & $-8.383^{* * *}$ & [1] (1) & $-6.448^{* * *}$ & [1] (2) \\
\hline \multicolumn{7}{|l|}{$\mathrm{PP}$} \\
\hline Level & -2.857 & [3] (2) & -2.543 & [2] (1) & -2.592 & [3] (2) \\
\hline First difference & $-13.883^{* * *}$ & [1] (0) & $-12.910^{* * *}$ & [1] (6) & $-13.269^{* * *}$ & {$[1](5)$} \\
\hline \multicolumn{7}{|l|}{ NP } \\
\hline Level & -0.487 & [2] $(0)$ & -2.118 & [3] $(0)$ & -2.009 & {$[3](6)$} \\
\hline First difference & $-3.016^{* *}$ & [3] (9) & $-4.351^{* * *}$ & [3] (9) & $-4.216^{* * *}$ & [3] (2) \\
\hline
\end{tabular}

Notes: (1) JP Stock, TW Stock, and EX Rate are the symbols for the Nikkei Index, Taiwan Stock Exchange Index and NTD/Yen exchange rate, respectively. (2)***, **, and * denote significance at $1 \%, 5 \%$, and $10 \%$ levels, respectively. (3) The critical values for $1 \%, 5 \%$, and $10 \%$ levels of ADF, PP and NP, are (-4.011663, -3.435858, and -3.141996), $(-4.011663,-3.435858$, and -3.141996$)$ and $(-3.42000,-2.91000$, and -2.62000$)$, respectively. The critical values for the ADF $t$-statistics are from the Mackinnon (1996) table. (4) The test statistic of the NP test is $\mathrm{MZ}_{t}$. (5) The numbers in the brackets indicate model specification. The numbers in the parentheses of ADF, and NP are the appropriate lag lengths selected by MAIC, whereas the numbers in the parentheses of PP is the optimal bandwidths decided by the Bartlett kernel of Newey and West (1994). (6) The appropriate models selected for the level and the first difference are based on the decision procedures suggested by Dolado et al. (1990).

Table 2

The results of ZA unit-root tests with structural break

\begin{tabular}{lllll}
\hline & Break & Level $\left(t\left(\hat{\lambda}_{\text {inf }}\right)\right)$ & Break & First difference $\left(t\left(\hat{\lambda}_{\text {inf }}\right)\right)$ \\
\hline JP Stock & $1992: 06$ & $-4.025(\mathrm{C})$ & $2002: 12$ & $-5.553(\mathrm{~A})^{* * * *}$ \\
TW Stock & $2000: 07$ & $-3.895(\mathrm{~B})$ & $1997: 07$ & $-8.675(\mathrm{~A})^{* * * *}$ \\
EX Rate & $1993: 01$ & $-3.061(\mathrm{~B})$ & $1997: 06$ & $-6.750(\mathrm{~A})^{* * *}$
\end{tabular}

Notes: (1) *** denotes significance at $1 \%$ level. (2) The critical value for $1 \%, 5 \%$, and $10 \%$ levels are $(-5.34,-4.80$, and -4.58), (-4.93, -4.42, and -4.11), and (-5.57, -5.08, and -4.82) for Model A, Model B, and Model C, respectively, from Zivot and Andrews (1992). (3) The characters within the parenthesis indicate the appropriate model according to the results from ADF test. (A), (B) and (C) represent Eqs. (4), (5) and (6), respectively.

Table 3

Determination of co-integration rank in consideration of a linear trend and a quadratic trend

\begin{tabular}{|c|c|c|c|c|c|c|c|c|c|c|}
\hline \multirow[t]{2}{*}{ Rank } & \multicolumn{2}{|c|}{ Model $1 \mathrm{H}_{0}$} & \multicolumn{2}{|c|}{ Model $2 \mathrm{H}_{1}^{*}$} & \multicolumn{2}{|c|}{ Model $3 \mathrm{H}_{1}$} & \multicolumn{2}{|c|}{ Model $4 \mathrm{H}_{2}^{*}$} & \multicolumn{2}{|c|}{ Model $5 \mathrm{H}_{2}$} \\
\hline & $T_{0}(r)$ & $C_{0}(5 \%)$ & $T_{1}^{*}(r)$ & $C_{1}^{*}(5 \%)$ & $T_{1}(r)$ & $C_{1}(5 \%)$ & $T_{2}^{*}(r)$ & $C_{2}^{*}(5 \%)$ & $T_{2}(r)$ & $C_{2}(5 \%)$ \\
\hline$r=0$ & 14.4 & 24.3 & 26.2 & 35.2 & 23.4 & 29.8 & 36.0 & 42.9 & 34.5 & 35.0 \\
\hline$r \leq 1$ & 5.8 & 12.3 & 11.5 & 20.2 & 9.6 & 15.5 & 18.2 & 25.9 & 16.9 & 18.4 \\
\hline$r \leq 2$ & 0.1 & 4.1 & 5.2 & 9.2 & $\underline{4.0}$ & 3.8 & 4.7 & 12.5 & 4.3 & 3.8 \\
\hline
\end{tabular}

Notes: (1) $T_{0}(r), T_{1}^{*}(r), T_{1}(r), T_{2}^{*}(r)$, and $T_{2}(r)$ denote the LR test statistics for all the nulls of $\mathrm{H}(r)$ vs. the alternative of $\mathrm{H}(p)$ of Johansen's five models. (2) $C_{0}(5 \%), C_{1}^{*}(5 \%), C_{1}(5 \%), C_{2}^{*}(5 \%)$, and $C_{2}(5 \%)$ are the $5 \%$ LR critical values for Johansen's five models, which are extracted from Osterwald-Lenum (1992). (3) The model selection follows Nieh and Lee's (2001) decision procedure, diagnosing models one by one until the model that cannot be rejected for the null. (4) The bold number with underline indicates the selection of the rank in the presence of linear deterministic trend. (5) VAR length is 2 for all the models, which is selected based on the smallest number of AIC. 
Zivot-Andrews Unit Root Test on JP Stock
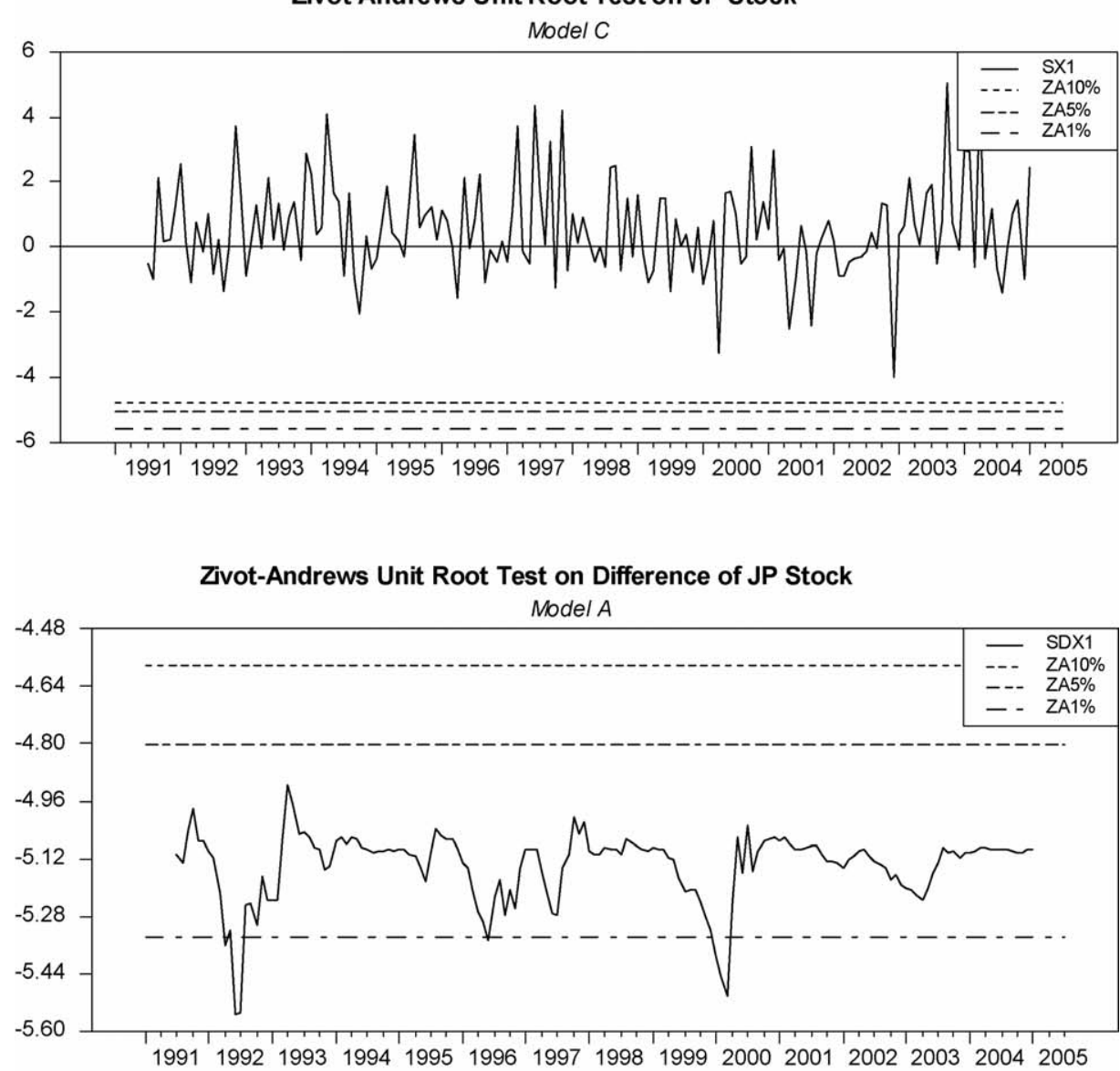

Zivot-Andrews Unit Root Test on TW Stock

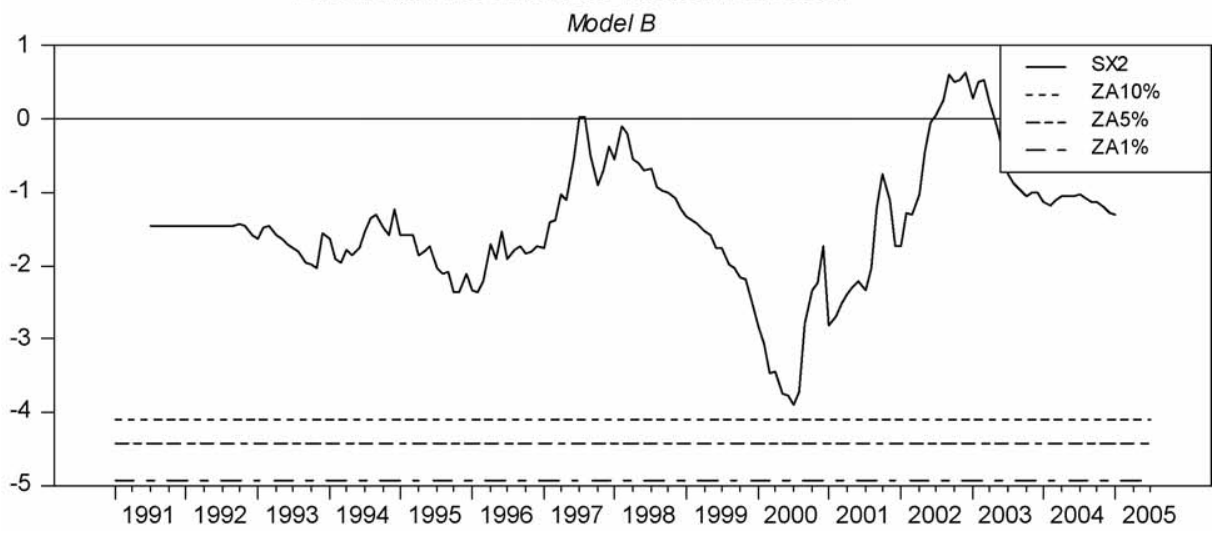

Fig. 2. Zivot-Andrews unit root tests on NTD/Yen exchange rate, JP stock and TW stock. 


\section{Zivot-Andrews Unit Root Test on Difference of TW Stock}

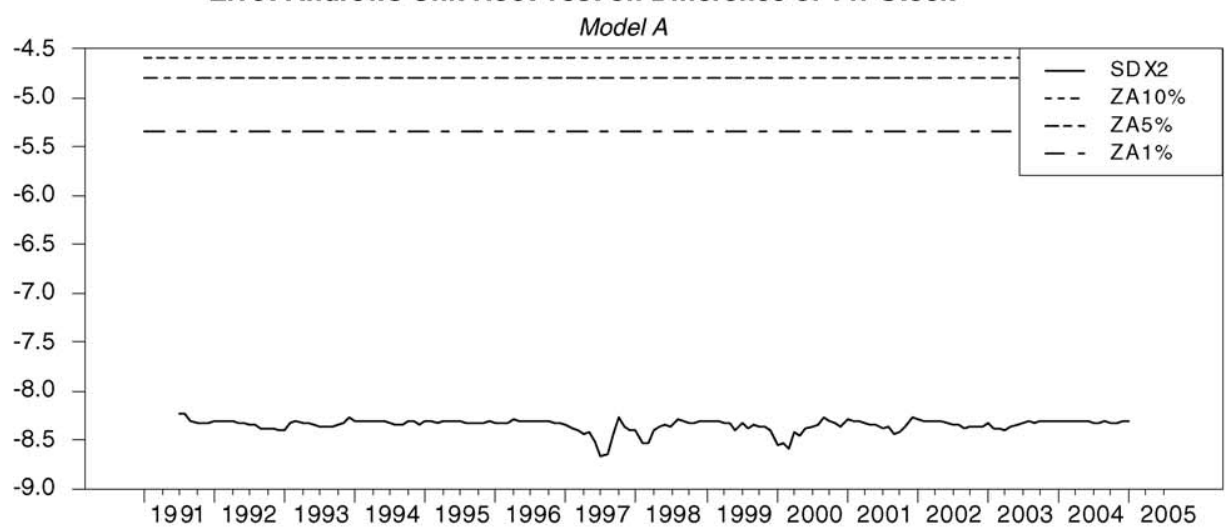

Zivot-Andrews Unit Root Test on NTD/Yen Exchange Rate

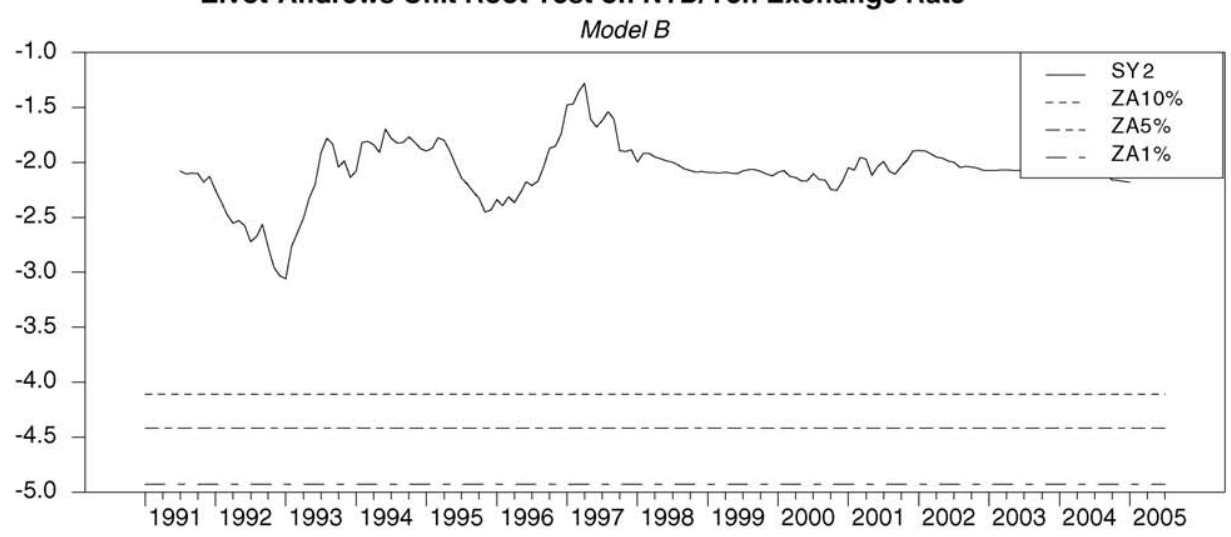

Zivot-Andrews Unit Root Test on Difference of NTD/Yen Exchange Rate

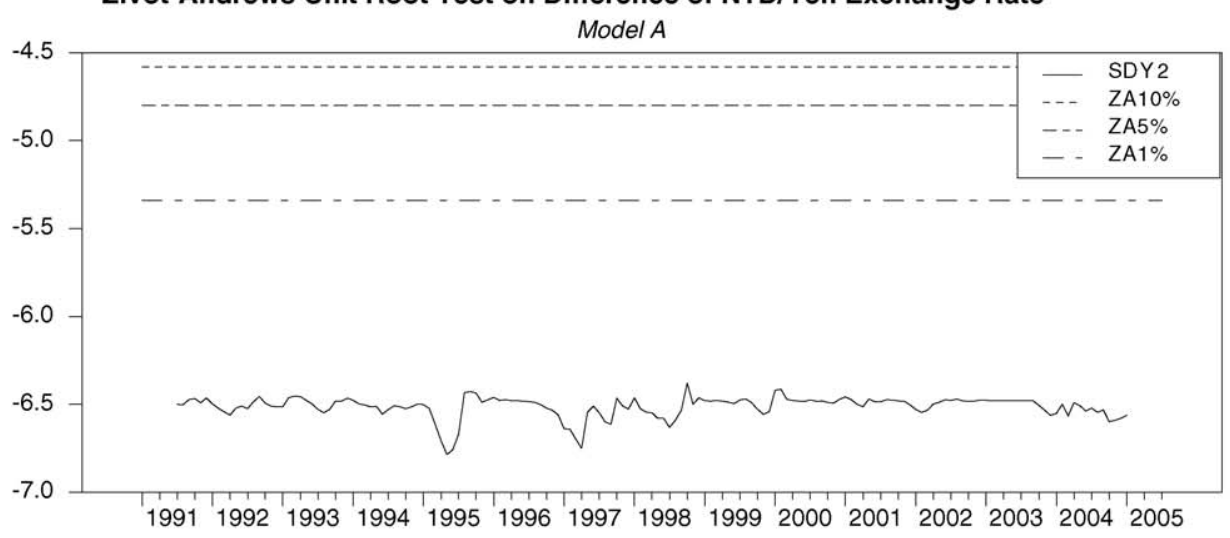

Fig. 2. (Continued). 
Table 4

The results of GH co-integration test with structural break

\begin{tabular}{lllr}
\hline & $\mathrm{ADF}^{*}$ & $Z_{t}^{*}$ & $Z_{\alpha}^{*}$ \\
\hline$C$ & $-4.798(0.400)$ & $-4.812(0.400)$ & $-39.645(0.400)$ \\
$C / T$ & $-4.235(0.434)$ & $-4.214(0.417)$ & $-31.346(0.417)$ \\
$C / S$ & $-4.798(0.400)$ & $-4.812(0.400)$ & $-40.118(0.400)$ \\
\hline
\end{tabular}

Notes: (1) Critical values for model $C, C / T$ and $C / S$ are $-4.92,-5.29,-5.50$ for $\mathrm{ADF}^{*}$ and $Z_{t}^{*}$ and $-46.98,-53.92$, -58.33 for $Z_{\alpha}^{*}$, respectively (see Gregory and Hansen (1996), Table 1, p. 109). (2) Numbers in the parentheses are the point of structural break represented by the percentage of the whole sample period.

Table 5

Pairwise Granger causality tests

\begin{tabular}{lc}
\hline Null hypothesis & Probability \\
\hline JP Stock does not Granger cause EX Rate & 0.6197 \\
EX Rate does not Granger cause JP Stock & 0.4588 \\
TW Stock does not Granger cause EX Rate & 0.2608 \\
EX Rate does not Granger cause TW Stock & 0.7209 \\
TW Stock does not Granger cause JP Stock & $0.0059^{* * *}$ \\
JP Stock does not Granger cause TW Stock & $0.0376^{* *}$ \\
\hline
\end{tabular}

Notes: (1) TW Stock, JP Stock and EX Rate are the symbols for stock prices of Taiwan, Japan and the exchange rate of the NTD/Yen, respectively. (2) ***,** denote significance at the $1 \%$ and $5 \%$ significant level. (3) The null hypothesis, $\mathrm{H}_{0}$, is for "no causal relation". (4) Lag length is 2 selected by AIC.

However, there is no significant lead-lag causal relationship found between the NTD/Yen exchange rate and stock prices of Taiwan or Japan in the short run.

Owing to the advantage of being invariant to the ordering of the variables the G-IRF and GVDC are employed in this study. The results of G-IRF and G-VDC are exhibited in Fig. 3 and Table 6, respectively. Firstly, via G-IRFs, it shows that the JP stock and TW stock interact with each other; whereas with a permanent effect of the response of TW stock to the shock of the JP stock, and a transitory effect of the response of JP stock in the reverse direction. ${ }^{19}$ Moreover, the response of NTD/Yen to JP stock is trivial, whereas the NTD/Yen has an increasing influence on JP stock conversely. Moreover, the impulse response to each other between NTD/Yen and TW stock starts out being negative in the short run and turns to positive in the long run. The transition points are in the fourth month for the response of TW stock to NTD/Yen; and in the sixth month for the response of NTD/Yen to TW stock. It reveals that the portfolio approach is supported in the short run especially before the sixth month; while in the long run (after the fourth month) the traditional approach is more applicable. The last finding from the G-IRFs in Fig. 3 shows that the responses due to their own shocks (self-responses) exist apparently for both stock prices of Japan and Taiwan; whereas the self-response of NTD/Yen exchange rate is not significant, even decreasing as time goes by.

The further finding of G-VAR is from the implementation of G-VDC. We observed from Table 5 that the self-explained power dominated for each of the three variables considered, which

\footnotetext{
${ }^{19}$ For the transmission effects of IRF, Lutkepohl and Reimers (1992) distinguished between transitory and permanent effects by the argument that an effect of a one-time impulse on a variable is called transitory (permanent) if the variable (does not) return(s) to it's previous equilibrium value of zero after some period.
} 
Response of EX_RATE to EX_RATE

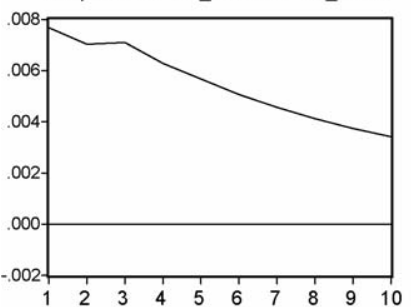

Response of JP_STOCK to EX_RATE

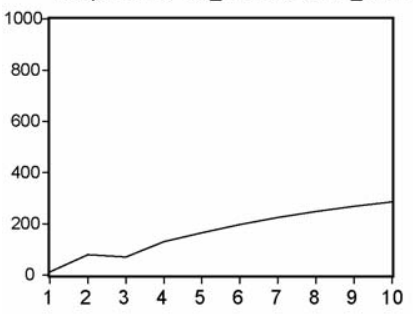

Response of TW_STOCK to EX_RATE

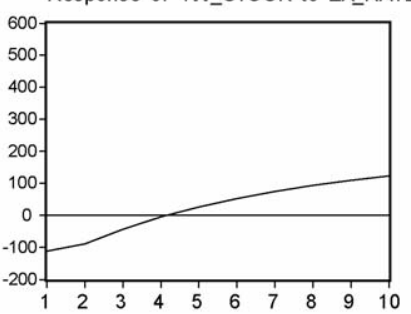

Response to Generalized One S.D. Innovations

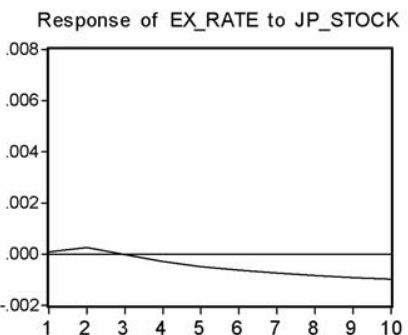

Response of EX_RATE to TW_STOCK

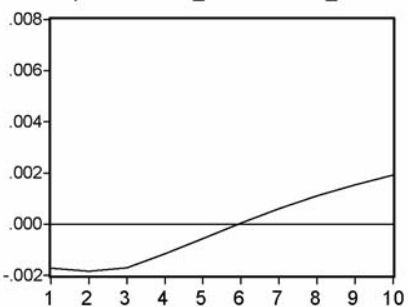

Response of JP_STOCK to JP_STOCK

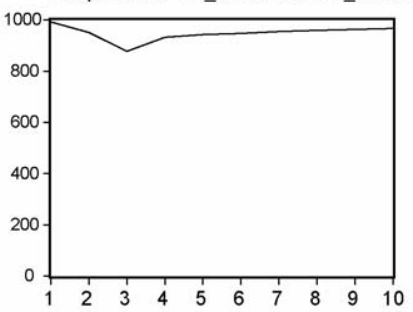

Response of JP_STOCK to TW_STOCK

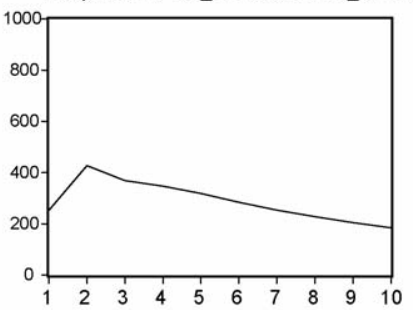

Response of TW_STOCK to TW_STOCK

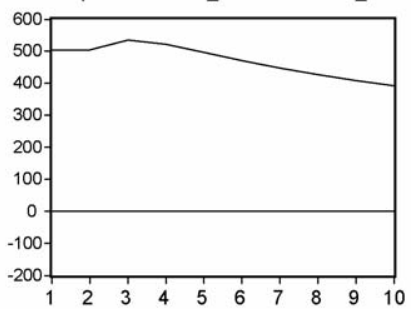

Fig. 3. Generalized-impulse response functions.

Table 6

The results of the forecast error variance decomposition

\begin{tabular}{lrrrr}
\hline & Period & EX Rate & JP Stock & TW Stock \\
\hline EX Rate & 1 & 100.00 & 0.00 & 0.00 \\
& 4 & 99.78 & 0.09 & 0.13 \\
& 7 & 97.02 & 0.56 & 2.43 \\
JP Stock & 10 & 90.26 & 1.22 & 8.52 \\
& 1 & 0.02 & 99.98 & 0.00 \\
& 4 & 0.78 & 96.64 & 2.58 \\
TW Stock & 7 & 2.25 & 95.89 & 1.86 \\
& 10 & 3.82 & 94.89 & 1.29 \\
& 1 & 4.95 & 6.67 & 88.38 \\
& 4 & 2.05 & 6.21 & 91.73 \\
& 7 & 1.70 & 10.32 & 89.85 \\
\hline
\end{tabular}

Notes: (1) Each number is in a percentage value. (2) The values of the variance decomposition decomposes forecast error variance (FEV) in an endogenous variable into percentage shocks to its own and other endogenous variables in the VAR, which in turn offers information about the relative importance of each random innovation to the variables. 
implies each variable has the greatest explanatory portion in describing the FEVs of its own shocks. Other describable results are that the variance or volatility of TW stock can be explained by JP stock as time goes by (i.e. decomposed portion of $10.32 \%$ in the tenth month), while changes in TW stock has some influence to explain the volatility of NTD/Yen exchange rate as time goes by (i.e. $8.52 \%$ in the tenth month).

\section{Conclusion}

This study attempts to employ both the conventional and advanced time series methodologies, incorporating endogenous structural break to explore the dynamic short-term and long-term interrelationships among the NTD/Yen exchange rate and stock prices of Taiwan and Japan. Firstly, it is found that from both conventional ADF, PP, and NP tests and advanced ZA test with structural break, all variables are insured I(1) non-stationary time series. For the long-term equilibrium relationship, the results of conventional Johansen test and advanced GH test are consistent. Since the advanced GH co-integration test with structural break expands Johansen's linear model specification, the finding from GH test with no long-term co-movement among the three variables confirms the previous result from Johansen's tests. This further conclusion of no long-term equilibrium between stock prices and exchange rates is consistent with the findings of Nieh and Lee (2001) and Bahmani-Oskooee and Sohrabian (1992). Furthermore, the results of the Granger causality test show that bi-directional feedback relationship between stock prices of Taiwan and Japan are significant. However, there is no significant linkage or causal relationship found between each of the stock prices and the NTD/ Yen exchange rate. The main reason could be that maintaining a stable exchange rate is the common objective of the governments and central banks of both countries. Therefore, the exchange rate does not interact frequently with prices fluctuations. This result differs from the finding of Granger et al. (2000), which is possibly because of the Japanese Yen being used instead as the base-currency in this paper. The linkage among the USD, Yen, and NTD, and the interactions within them may be extended as a further research.

Regarding the impact innovations, some interesting findings are from the G-IRF. Firstly, the stock prices of Japan and Taiwan interact with each other, whereas with a permanent effect of JP stock on TW stock and a transitory effect of TW stock on JP stock. Secondly, the shock of NTD/ Yen has an increasing influence on JP stock; whereas the response of NTD/Yen to the shock of JP stock is trivial. The positive impact of NTD/Yen on JP stock is just contrary to the traditional approach, which may be interpreted as that Japan is more like an import-led country while having lots of trade with Taiwan. Thirdly, the impulse response to each other between NTD/Yen and TW stock starts out being negative in the short run and turns to positive in the long run. This reveals that the portfolio approach is supported in the short run especially before the sixth month; while in the long run (after the fourth month) the traditional approach is more applicable. The final implications from the results of G-VDC indicate that each variable has the greatest explanatory portion in describing the FEVs of its own shocks. Also, the variance of TW stock can be explained by JP stock and NTD/Yen exchange rate by TW stock, respectively, as time goes by.

Japanese Yen is considered as a hard currency in contrast to the NTD; therefore it is assumed that the central bank of Japan has a dominant power over the trend of the NTD/Yen exchange rate. The central bank may adopt a monetary policy, which may benefit the stock price of Japan. However, from the results of the FEVs, the volatility of NTD/Yen exchange rate can be explained by the changes in TW stock as time goes by but not the JP stock. This leads to a question that stabilizing or monetary function of policy shocks varies across countries. The exchange rate 
intervention is beyond the scope of this paper, and the topic may be considered as a direction for future study.

The overall conclusion can be drawn that the long-term equilibrium relationship among NTD/ Yen exchange rate and stock prices of Taiwan and Japan does not exist. However, for the shortterm effects, stock prices of Taiwan and Japan interact with each other, with the impact of JP stock on TW stock persists for longer periods. Besides, for the relationship between each of the stock price and exchange rate, the portfolio approach is supported in the short run and the traditional approach is more plausible in the long run in the financial market of Taiwan. Whereas, in the Japanese market, Japan is found to be more like an import-led country, with lots of trade with Taiwan since the traditional approach applied in Japan's case is just the reverse. Moreover, the portfolio approach is not suitable to Japan's market. It is believed that individual investors as well as financial institutions in Taiwan and Japan can benefit from the findings in this study to better strategize their stock investment and asset allocation.

\section{Acknowledgement}

The authors acknowledge Professor Dutta for his valuable comments and suggestions in the 2005 International Conference on Business and Finance held in Tamkang University, Taiwan. Those comments have greatly enhanced the quality of this paper.

\section{Reference}

Abdalla, I. S. A., \& Murinde, V. (1997). Exchange rates and stock price interactions in emerging financial markets: Evidence on India, Korea and the Philippines. Applied Financial Economics, 7, 25-35.

Aggarwal, R. (1981). Exchange rates and stock prices: A study of the U.S. capital markets under floating exchange rates. Akron Business and Economic Review, 7-12.

Ajayi, R. A., \& Mougoue, M. (1996). On the dynamic relation between stock prices and exchange rates. The Journal of Financial Research, 19, 193-207.

Ayat, L., \& Burridge, P. (2000). Unit root tests in the presence of uncertainty about the non-stochastic trend. Journal of Econometrics, 95(1), 71-96.

Bahmani-Oskooee, M., \& Sohrabian, A. (1992). Stock prices and the effective exchange rate of the dollar. Applied Economics, 24(4), 459-464.

Barton, E., \& Bodnar, G. M. (1994). Firm valuation, earning expectations, and the exchange rate exposure effect. Journal of Finance, 49(5), 1755-1786.

Bhattacharya, B., \& Mukherjee, J. (2003). Causal relationship between stock market and exchange rate. foreign exchange reserves and value of trade balance: A case study for India. Paper presented at the Fifth Annual Conference on Money and Finance in the Indian Economy on January 2003.

Bodnar, G. M., \& Gentry, W. M. (1993). Exchange rate exposure and industry characteristics: Evidence from Canada, Japan and U.S.. Journal of International Money and Finance, 12, 29-45.

Caporale, G. M., Pittis, N., \& Spagnolo, N. (2002). Testing for causality-in-variance: An application to the East Asian markets. International Journal of Finance and Economics, 7(3), 235-245.

Chen, S.-L., \& Wu, J.-L. (1997). Sources of real exchange-rate fluctuations: Empirical evidence from four pacific basin countries. Southern Economic Journal, 63(3), 776-787.

Chiao, C., Hung, K., \& Nwanna, G. I. (2001). The impact of market liberalization on firms' exchange rate exposure. Competitiveness Review, 11(1), 40-52.

Choi, J. J., \& Prasad, A. M. (1995). Exchange risk sensitivity and its determinants: A firm and industrial analysis of U.S. multinationals. Financial Management, 24(3), 77-88.

Choi, J. J., Hiraki, T., \& Takezawa, N. (1998). Is foreign exchange risk priced in the Japanese stock market? Journal of Financial and Quantitative Analysis, 33(3), 361-382.

Cooley, T. F., \& LeRoy, S. F. (1985). Atheoretical macroeconometrics-A critique. Journal of Monetary Economics, 16 , 283-308. 
Dekker, A., Sen, K., \& Young, M. R. (2001). Equity market linkages in the Asia Pacific region: A comparison of the orthogonalized and generalized VAR approaches. Global Finance Journal, 12(1), 1-33.

Dickey, D. A., \& Fuller, W. A. (1981). Likelihood ratio statistics for autoregressive time series with unit root. Econometrica, 49, 1057-1072.

Dolado, J. J., Jenkinson, T., \& Sosvilla-Rivero, S. (1990). Co-integration and unit roots. Journal of Economic Surveys, 4 , $249-273$.

Doukas, J., Hall, P. H., \& Lang, L. H. P. (1999). The pricing of currency risk in Japan. Journal of Banking and Finance, 23(1), 1-20.

Dropsy, V., \& Nazarian-Ibrahimi, F. (1994). Macroeconomic policies, exchange rate regimes and national stock markets. International Review of Economics and Finance, 3(2), 195-220.

Durand, R. B., Kee, K. S., \& Watson, I. (2001). Who moved Asian-Pacific stock markets? A further consideration of the impact of the US and Japan. Australian Journal of Management, 26(2), 125-145.

Elder, J., \& Kennedy, P. E. (2001). Testing for unit roots: What should student be taught? Journal of Economic Education, 32(2), 137-146.

Elyasiani, E., \& Mansur, I. (2005). The association between market and exchange rate risks and accounting variables: A GARCH model of the Japanese banking institutions. Review of Quantitative Finance and Accounting, 25(2), 183-206.

Enders, W., \& Hurn, S. (1994). Theory and tests of generalized of purchasing power parity: Common trends and real exchange rates in the Pacific rim. Review of International Economics, 2(2), 179-190.

Engle, R., \& Granger, C. (1987). Co-Integration and error correction representation, estimation and testing. Econometrica, 55, 251-267.

Ewing, B. T. (2003). The response of the default risk premium to macroeconomic shocks. Quarterly Review of Economics and Finance, 43(2), 261-272.

Fang, H., \& Loo, J. C. H. (1996). Foreign exchange risk and common stock returns: A note on international evidence. Journal of Business Finance and Accounting, 23(3), 473-480.

Gonzalo, J. (1994). Five alternative methods of estimating long-run equilibrium relationships. Journal of Econometrics, $60,203-233$.

Granger, C. W. J. (1969). Investigating causal relations by econometric models and cross-spectral methods. Econometrica, 37, 24-36.

Granger, C. W. J., Huang, B. N., \& Yang, C. W. (2000). A bivariate causality between stock prices and exchange rates: Evidence from recent Asian flu. Quarterly Review of Economics and Finance, 40, 337-354.

Gregory, A., \& Hansen, B. (1996). Residual-based tests for co-integration in models with regime shifts. Journal of Econometrics, 70, 99-126.

Guo, J.-T., \& Wu, R.-C. (1998). Financial liberalization and the exchange-rate exposure of the Taiwanese firms: A nonparametric analysis. Multinational Finance Journal, 2(1), 37-61.

Hacker, R. S., \& Hatemi-J, A. (2003). Is the J-curve effect observable for small North European economies? Open Economies Review, 14(2), 119-134.

Hamilton, J. D. (1994). Time series analysis. Princeton, NJ: Princeton University Press.

He, J., \& Ng, L. K. (1998). The foreign exchange exposure of Japanese multinational corporations. The Journal of Finance, 53(2), 733-754.

Homma, T., Tsutsui, Y., \& Benzion, U. (2005). Exchange rate and stock prices in Japan. Applied Financial Economics, 15(7), 469-478.

Johansen, S. (1988). Statistical analysis of co-integration vectors. Journal of Economics and Dynamics and Control, 12 , 231-254.

Johansen, S. (1990). Determination of co-integration rank in the presence of a linear trend. Oxford Bulletin of Economics and Statistics, 54(3), 383-397.

Johansen, S. (1994). The role of the constant and linear terms in co-integration analysis of non-stationary variables. Econometric Review, 13(2), 205-229.

Johansen, S., \& Juselius, K. (1990). Maximum likelihood estimation and inference on co-integration with applications to the demand for money. Oxford Bulletin of Economics and Statistics, 52(2), 169-210.

Kanas, A. (2000). Volatility spillovers between stock returns and exchange rate changes: International evidence. Journal of Business and Accounting, 27(3-4), 447-467.

Karolyi, G. A., \& Stulz, R. M. (1996). Why do markets move together? An investigation of U.S.-Japan stock return comovements. The Journal of Finance, 51(3), 951-986.

King, R., Plosser, C. I., Stock, J. H., \& Watson, M. M. (1991). Stochastic trends and economic fluctuations. American Economic Review, 819-840. 
Koop, G., Pesaran, M. H., \& Potter, S. M. (1996). Impulse response analysis in non-linear multivariate models. Journal of Econometrics, 74(1), 119-147.

Kwon, C. S., Shin, T. S., \& Bacon, F. W. (1997). The effect of macroeconomic variables on stock markets returns in developing markets. Multinational Business Review, 5, 63-70.

Lutkepohl, H., \& Reimers, H. E. (1992). Impulse response analysis of co-integrated systems. Journal of Economic Dynamics and Control, 16, 53-78.

Mackinnon, J. G. (1996). Numerical distribution functions for unit root and co-integration tests. Journal of Applied Econometrics, 601-618.

Mok, H. (1993). Causality of interest rate, exchange rate and stock price at stock market open and close in Hong Kong. Asia Pacific Journal of Management, 10, 123-143.

Newey, W., \& West, K. (1994). Automatic lag selection in covariance matrix estimation. Review of Economic Studies, 61, 631-653.

Ng, S., \& Perron, P. (2001). Lag length selection and the construction of unit root tests with goof size and power. Econometrica, 69, 1519-1554.

Nieh, C. C., \& Lee, C. F. (2001). Dynamic relationship between stock prices and exchange rates for G-7 countries. Quarterly Review of Economics and Finance, 41(4), 477-490.

Osterwald-Lenum, M. (1992). Practitioner's Corner-A note with quantiles of the asymptotic distribution of the maximum likelihood co-integration rank test statistics. Oxford Bulletin of Economics and Statistics, 54, 461-472.

Pantula, S. G. (1989). Testing for unit roots in time series data. Econometric Theory, 5, 256-271.

Peel, D. A., \& Venetis, I. A. (2003). Purchasing power parity over two centuries: Trends and non-linearity. Applied Economics, 35(5), 609-617.

Perron, P. (1989). The great crash, the oil price shock and the unit root hypothesis. Econometrica, 57, 1361-1401.

Pesaran, M. H., \& Shin, Y. (1998). Generalized impulse response analysis in linear multivariate models. Economic Letters, $58,17-29$.

Phillips, P. C. B., \& Perron, P. (1988). Testing for a unit root in time series regression. Biometrika, 75, 335-346.

Pilbeam, K. (2001). The East Asian Financial Crisis: Getting to the heart of the issues. Managerial Finance, 27(1-2), 111133.

Prasad, A. M., \& Rajan, M. (1995). The role of exchange and interest risk in equity valuation: A comparative study of international stock markets. Journal of Economics and Business, 47(5), 457-472.

Schwert, G. W. (1989). Tests for unit roots: A Monte Carlo investigation. Journal of Business and Economic Statistics, 7 , $147-159$.

Sewell, S. P., Stansell, S. R., Lee, I., \& Below, S. D. (1996). Using chaos measures to examine international capital market integration. Applied Financial Economics, 6(2), 91-101.

Smith, C. E. (1992). Stock markets and the exchange rate: A multi-country approach. Journal of Macroeconomics, 14(4), 607-629.

Soenen, L. A., \& Hennigar, E. S. (1988). An analysis of exchange rates and stock prices-The U.S. experience between 1980 and 1986. Akron Business and Economic Review, 19, 7-16.

Sun, Q., \& Tong, W. H. S. (2000). The effect of U.S. trade deficit announcements on the stock prices of U.S. and Japanese automakers. The Journal of Financial Research, 23(1), 15-43.

Varela, O., \& Naka, A. (1997). The London International Stock Exchange's foreign currency exposures to the Dollar, Yen and Mark. Managerial Finance, 23(7), 45-57.

Wu, J.-L. (1997). Foreign exchange market efficiency and structural instability: Evidence from Taiwan. Journal of Macroeconomics, 19(3), 591-607.

Zhou, S. (1996). The response of real exchange rates to various economic shocks. Southern Economic Journal, 61(4), 936-954.

Zivot, E., \& Andrews, D. W. K. (1992). Further evidence on the great crash, the oil price shock, and the unit root hypothesis. Journal of Business and Economic Statistics, 10, 251-270. 